\title{
PENGARUH PEMBANGUNAN PLAZA ALDIRON TERHADAP TINGKAT PENDAPATAN PEDAGANG TRADISIONAL DI EKS PASAR CINDE KOTA PALEMBANG
}

\author{
Oleh: Eka Meirawati ${ }^{*}$, Dwirini ${ }^{*}$ Eka Rostartina ${ }^{3}$ \\ e.meirawati@yahoo.com ${ }^{1 *}$, dwirini_d14@yahoo.com ${ }^{2 *}$, ekarostartina@unsri.ac.id ${ }^{3}$ \\ (Program Studi Akuntansi, Fakultas Eknomi Universitas Sriwijaya)
}

\begin{abstract}
Abstrak-Pusat perbelanjaan di Palembang telah mengalami kemajuan yang pesat seiring dengan berkembangnya Kota Palembang dengan pembangunan berbagai infrastruktur yang prestisius. Hal tersebut terkait erat dengan agenda besar perhelatan Asian Games dan Moto GP pada tahun 2018 yang lalu. Keberadaan pasar tradisional termasuk salah satu variabel paling nyata kegiatan ekonorni masyarakat di suatu wilayah. Tujuan penelitian ini untuk mengetahui pengaruh pendapatan pedagang di tradisional Plaza Aldiron Cinde sebelum dan ketika pembangunan pasar berbeda secara signifikan. Metode penelitiannya adalah analisis regresi berganda menggunakan secara simultan (uji F) pada level significance 5\%. Hasil uji hipotesis secara uji simultan (uji F) pada Tabel 7.12 menunjukkan bahwa diperoleh besarnya probabilitas sebesar 0,000 <0,05. Dengan demikian, dalam penelitian ini menyatakan ada pengaruh yang signifikan dari sebelum dan ketika ada pembangunan Plaza Aldiron sebagai variabel bebas secara simultan terhadap pendapatan pedagang sebagai variabel terikat.
\end{abstract}

Kata Kunci : Pendapatan, Revitalisasi Pasar, PSAK No.23

Abstract-Shopping centers in Palembang have experienced rapid progress along with the development of Palembang City with the construction of various prestigious infrastructures. This is closely related to the big agenda for the Asian Games and Moto GP events in 2018. The existence of traditional markets is one of the most obvious variables of community economic activities in a region. The purpose of this study is to determine the effect of income of traders in the traditional Plaza Aldiron Cinde before and when the market development is significantly different. The research method is multiple regression analysis using simultaneous ( $F$ test) at the level of significance of 5\%. The results of the simultaneous hypothesis test ( $F$ test) in Table 7.12 show that the probability value is $0.000<0.05$. Thus, this study states that there is a significant influence from before and when there was the construction of Plaza Aldiron as an independent variable simultaneously on merchants' income as the dependent variable.

Keywords: Income, Market Revitalization, PSAK No.23

\section{PENDAHULUAN}

Kota Palembang adalah kota terbesar kedua di Sumatera setelah Kota Medan merupakan salah satu kota yang sudah berkembang baik dalam pendidikan, teknologi dan industri. Banyak pembangunan terjadi di kota ini khususnya pusat industri perbelanjaan yang akhir-akhir ini sedang bermunculan. 


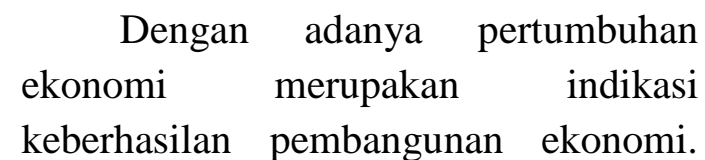
Demikian pula kehadiran pasar modern disatu pihak dapat menghambat pertumbuhan pedagang tradisional. Pedagang tradisional karena dari berbagai studi mengindikasikan adanya pengaruh negatif bagi pelaku usaha kecil, terutama yang bergerak disektor perdagangan. Walaupun, dipihak lain, pasar modern justru menjadi indikator kemajuan suatu daerah (Sitepu, 2011).

Wiboonpongse dan Sriboonchitta (2006) mengemukakan bahwa salah satu penyebab kurang berkembangnya pasar tradisional adalah minimnya daya dukung karakteristik pedagang tradisional, yakni strategi perencanaan yang kurang baik, terbatasnya akses permodalan yang disebabkan jaminan (collateral) yang tidak mencukupi, tidak adanya skala ekonomi (economies of scale), tidak ada jalinan kerja sama dengan pemasok besar, buruknya manajemen pengadaan, dan ketidakmampuan untuk menyesuaikan dengan keinginan konsumen.

Penelitian Lembaga ACNielsen (2005) menemukan fakta, bahwa pada tahun 2004, kontribusi pasar tradisional sekitar 69,9\%, menurun dari tahun sebelumnya yaitu 73,7\% (2003), 74,8\% (2002), 75,2\% (2001), dan 78,1\% (2000). Kondisi sebaliknya terjadi pada supermarket dan hypermarket, kontribusi mereka kian hari kian besar. Lebih lanjut hasil penelitian Suryadarma et al (2007) memperoleh temuan bahwa pasar tradisional yang berada dekat dengan supermarket terkena dampak yang lebih buruk dibanding yang berada jauh dari supermarket. Hal ini menunjukkan bahwa kinerja pasar tradisional cenderung mengalami penurunan walaupun tidak sepenuhnya karena keberadaan pasar modern, kondisi sebaliknya kinerja pasar modern meningkat.

Hasil penelitian lain yang sejalan dengan penelitian ini, yaitu penelitian yang telah dilakukan oleh Dwi Eliyani (2012) dengan judul "Dampak Relokasi Pasar Imogiri Terhadap Kondisi Sosial Ekonomi Pedagang di Pasar Imogiri Kecamatan Imogiri Kabupaten Bantul". Mengemukakan bahwa relokasi pasar tersebut memberikan dampak positif terbukti dengan adanya peningkatan pendapatan dan terciptanya peningkatan interaksi yang baik.

Menurut Gubernur Sumsel Alex Noerdin di Griya Agung, sangat menyesalkan munculnya polemik yang cukup panjang terkait revitalisasi pasar cinde hingga mengakibatkan transformasi pasar cinde yang layak dan modern tertunda hingga beberapa tahun. Padahal seharusnya sudah bisa selesai sebelum Asian Games 2018. Sekarang masalah sudah selesai, jadi saya berharap jangan ada polemik lagi. Saya tidak memiliki kepentingan apapun, keinginan saya hanya ingin menjadikan pasar ini lebih baik dan layak, disamping itu gedung lama sangat berbahaya, kalau roboh siapa yang mau bertanggungjawab

(Sumeks, 10/8/2017). 
Beberapa hasil penelitian terdahulu menunjukkan masih adanya perbedaan hasil tentang ada tidaknya dampak keberadaan pasar modern terhadap pedagang di pasar tradisional. Selain itu, umumnya penelitian tentang dampak ritel modern terhadap kinerja pedagang di pasar tradisional mengambil wilayah perkotaan, padahal akhir-akhir ini ritel modern seperti Indomaret dan Alfamart sudah penetrasi sampai ke wilayah kecamatan.

Program revitalisasi ini diharapkan mampu mengatasi kelemahan utama pasar tradisional yang identik dengan masalah kotor, becek, dan bau, sehingga berdampak pada meningkatnya jumlah pengunjung pasar. Dengan bertambahnya jumlah pengunjung, maka diharapkan dapat meningkatkan pendapatan pedagang. Di pasar tradisional terdapat suatu komunikasi yang tidak akan ditemui di pusat perbelanjaan modern. Sistem tawar menawar dalam transaksi jual beli di pasar tradisional membuat suatu hubungan tersendiri antar penjual dan pembeli.

\begin{tabular}{ccc}
\multicolumn{2}{c}{ Menurut Ikatan } & Akuntan \\
Indonesia dalam PSAK & No.23, \\
pengertian & pendapatan & adalah
\end{tabular}

Pendapatan adalah arus masuk bruto dari manfaat ekonomi yang timbul dari aktivitas normal perusahaan selama suatu periode bila arus masuk itu mengakibatkan kenaikan ekuitas, yang tidak berasal dari kontribusi penaman modal. Pendapatan hanya terdiri dari arus masuk bruto dari manfaat ekonomi yang diterima dan dapat diterima oleh dirinya sendiri.
Definisi tersebut menjelaskan bahwa pendapatan merupakan peningkatan kotor aktiva atau penurunan kotor hutang yang diakui dan diukur sesuai dengan prinsip akuntansi yang diterima umum yang berasal dari aktivitas berorientasi laba yang dapat mempengaruhi ekuitas pemilik.

Pendapatan diukur dari barang dan jasa yang ditukarkan dalam suatu transaksi dimana nilai tersebut menggambarkan ekuivalen kas atau nilai tunai uang yang diterima dalam proses penukaran, dengan kata lain pendapatan dinyatakan dalam jumlah rupiah atau dalam satuan mata uang lainnya. Dalam beberapa kondisi dimana tidak ada nilai tukar ekuivalen, maka nilai pasar biasanya dipandang sebagai alat ukur yang relevan atas pendapatan.

Nilai tukar tersebut ditentukan oleh persetujuan antara pembeli atau konsumen. Pendapatan direalisasi karena adanya proses produksi dan/atau proses pemasaran yang dilakukan perusahaan. Proses produksi yang dimaksud adalah pengubahan sumber daya yang dimiliki menjadi barang atau jasa tersebut kepada konsumen.

Sedangkan biaya adalah penurunan manfaat ekonomi selama suatu periode akuntansi dalam bentuk arus kas keluar atau berkurangnya aktiva atas terjadinya kewajiban yang mengakibatkan penurunan ekuitas yang tidak menyangkut pembagian kepada penanam modal. Biaya tetap adalah biaya yang jumlah totalnya tidak berubah dengan adanya perubahan 
volume kegiatan dalam kisaran perubahan volume kegiatan tertentu. Biaya variabel adalah biaya yang berubah sebanding dengan perubahan volume kegiatan. (IAI 2004:18).

Menurut Mudrajad Kuncoro (2008), isu utama yang berkaitan dengan perkembangan pasar tradisional adalah sebagai berikut:

1. Jarak antara pasar tradisional dengan hypermarket yang saling berdekatan.

2. Tumbuh pesatnya minimarket (yang dimiliki pengelola jaringan) ke wilayah pemukiman.

3. Penerapan berbagai macam syarat perdagangan oleh ritel modern yang memberatkan pemasok barang.

4. Kondisi pasar tradisional secara fisik sangat tertinggal, maka perlu ada program kebijakan untuk melakukan pengaturan.

Untuk mengatasi berbagai permasalahan tersebut, dikembangkan berbagai upaya untuk mengembangkan pasar tradisional. Salah satunya dilakukan dengan pembangunan pasar tradisional, antara lain dengan mengupayakan sumber-sumber alternatif pendanaan untuk pemberdayaan, meningkatkan kompetensi pedagang dan pengelola, memprioritaskan kesempatan memperoleh tempat usaha bagi pedagang pasar tradisional yang telah ada sebelum dan ketika dilakukan renovasi atau relokasi, serta mengevaluasi pengelolaan.

\section{METODE PENELITIAN}

Jenis penelitian ini adaah kuantitatif deskriptif. Kuantitatif deskriptif adalah jenis penelitian yang diguanakan untuk menganalisis data dengan cara mendeskripsikan data yang telah terkumpul sesuai keadaan sebagaimana adanya.

Penelitian ini mengambil lokasi di Plaza Aldiron Cinde kota Palembang, karena pasar ini dijadikan pilot project pembangunan pasar di Kota Palembang. Pasar ini merupakan pasar tradisional yang diarahkan untuk menerapkan dan mengadopsi manajemen pasar modern. Pada tahap awal pembangunan dikhususkan pada penataan lingkungan fisik terutama meliputi penanganan kebersihan sehingga dapat menyerupai pasar modern. Objek dalam penelitian ini adalah pendapatan pedagang di Plaza Aldiron Cinde sebelum dan ketika dilakukan pembangunan pasar.

Populasi dalam penelitian ini adalah pedagang tradisional eks Pasar Cinde yang berada di wilayah Plaza Aldiron yaitu sebanyak 311 pedagang. Dalam penelitian ini diketahui $\mathrm{N}$ sebesar 311, e ditetapkan sebesar $10 \%$. Jadi jumlah minimal sampel yang diambil oleh peneliti adalah sebesar :

$$
\begin{aligned}
& N=\frac{N}{1+N e^{2}} \\
& N=\frac{311}{1+(311)(0,10)^{2}} \\
& N=\frac{311}{4,11} \\
& N=75,66
\end{aligned}
$$


Jumlah minimal sampel yang diambil sebesar 75,66 yang dibulatkan menjadi 76 pedagang. Berdasarkan perhitungan dengan rumus Slovin di atas jumlah sampel dalam penelitian ini kurang lebih 76 pedagang. Dalam hal ini sampel yang digunakan dalam penelitian ini adalah pengambilan sampel secara acak sederhana (simple random sampling) yaitu sebuah sampel yang diambil sedemikian rupa sehingga tiap unit penelitian atau satuan elementer dari populasi mempunyai kesempatan yang sama untuk dipilih sebagai sampel.

Analisis data dilakukan dengan serangkaian tahapan pengujian, mulai dari pengukuran instrumen yaitu pengujian validitas dan reliabilitas, normalitas, dan uji beda. Teknik yang digunakan untuk pengujian validitas dengan menggunakan teknik korelasi Pearson Correlation. Apabila Pearson Correlation yang didapat memiliki nilai di bawah 0,05 berarti data yang diperoleh adalah valid (Ghozali, 2005:45). sedangkan pengujian reliabilitas dilakukan dengan menggunakan koefisien Alpha Cronbach $\geq 0,6$. Sebelum dilakukan analisis statistik dengan uji beda, terlebih dahulu akan dilakukan uji normalitas dengan menggunakan grafik histogram.

\section{HASIL DAN PEMBAHASAN Karakteristik Responden}

Responden dalam penelitian ini adalah pedagang tradisional eks Pasar Cinde yang berada di wilayah Plaza
Aldiron. Berikut ini adalah deskripsi mengenai identitas responden penelitian yang terdiri dari jenis usaha, kepemilikan modal, status tempat usaha, dan lamanya bekerja pedagang.

a. Deskripsi responden berdasarkan jenis usaha pedagang (lihat tabel 1 di samping)

Dari data tersebut terlihat bahwa penjual kerupuk/kemplang dan penjual buah adalah jenis pekerjaan yang paling banyak terdapat di eks Pasar Cinde. Hal ini sangat berkaitan dengan konsumen yang sebagian besar ibu rumah tangga yang juga menyukai jenis dagangan tersebut.

b. Deskripsi responden berdasarkan kepemilikan modal (lihat tabel 2 di samping).

Tabel 2 tersebut menunjukkan bahwa sekitar 72 orang atau $95 \%$ responden didominasi oleh kepemilikan modal sendiri, dan sisanya sebesar 4 orang atau $5 \%$ responden oleh modal patungan.

c. Deskripsi responden berdasarkan lama usaha (lihat tabel 3 di samping).

Berdasarkan tabel lamanya usaha di dominasi pada rentang waktu di atas 16 tahun sebesar 24 responden atau sebesar $32 \%$. Lama bekerja pada rentang $1-5$ tahun sebesar 11 responden atau sebesar 14\%; rentang 6 - 10 tahun sebesar 21 responden atau sebesar $28 \%$; sebesar dan sisanya sebesar $26 \%$ atau 20 responden dengan rentang $11-15$ tahun. 
Tabel 1. Data Responden Berdasarkan Jenis Usaha Pedagang

\begin{tabular}{|c|l|c|c|}
\hline No. & \multicolumn{1}{|c|}{ Jenis Usaha Pedagang } & Jumlah & Persentase \\
\hline 1 & Penjual Daging & 3 & $4 \%$ \\
\hline 2 & Penjual Kembang & 5 & $7 \%$ \\
\hline 3 & Penjual Nasi (Makanan-Minuman) & 5 & $7 \%$ \\
\hline 4 & Penjual Kopi & 1 & $1 \%$ \\
\hline 5 & Penjual Kerupuk/ Kemplang & 12 & $16 \%$ \\
\hline 6 & Penjual alat-alat pertanian & 1 & $1 \%$ \\
\hline 7 & Penjual aksesoris TNI/ABRI & 6 & $8 \%$ \\
\hline 8 & Penjual ATK & 1 & $1 \%$ \\
\hline 9 & Penjual Baju & 2 & $3 \%$ \\
\hline 10 & Penjual Buah & 12 & $16 \%$ \\
\hline 11 & Penjual Kue & 7 & $9 \%$ \\
\hline 12 & Penjual Ikan & 3 & $4 \%$ \\
\hline 13 & Penjual Sayur & 2 & $3 \%$ \\
\hline 14 & Penjual Manisan & 3 & $4 \%$ \\
\hline 15 & Penjual Telur & 1 & $1 \%$ \\
\hline 16 & Penjual Gorengan & 2 & $3 \%$ \\
\hline 17 & Penjual sembako & 4 & $5 \%$ \\
\hline 18 & Penjual bumbu dapur/rempah-rempah & 4 & $5 \%$ \\
\hline 19 & Penjual Tape & 1 & $1 \%$ \\
\hline 20 & Penjual Plastik & 1 & $1 \%$ \\
\hline & & 76 & $100 \%$ \\
\hline
\end{tabular}

Sumber: Data Primer yang diolah, 2019

Tabel 2 Data Responden Berdasarkan Kepemilikan Modal

\begin{tabular}{|c|l|c|c|}
\hline No. & \multicolumn{1}{|c|}{ Kepemilikan Modal } & Jumlah & Persentase \\
\hline 1 & Modal sendiri & 72 & $95 \%$ \\
\hline 2 & Patungan & 4 & $5 \%$ \\
\hline & & 76 & $100 \%$ \\
\hline
\end{tabular}

Sumber: Data Primer yang diolah, 2019

Tabel 3. Data Responden Berdasarkan Lama Usaha

\begin{tabular}{|c|l|c|c|}
\hline No. & \multicolumn{1}{|c|}{ Lama Usaha Dagang } & Jumlah & Persentase \\
\hline 1 & $1-5$ tahun & 11 & $14 \%$ \\
\hline 2 & $6-10$ tahun & 21 & $28 \%$ \\
\hline 3 & $11-15$ tahun & 20 & $26 \%$ \\
\hline 4 & $>16$ tahun Jumlah & 24 & $32 \%$ \\
\hline & \multicolumn{2}{|c|}{76} & $100 \%$ \\
\hline
\end{tabular}

Sumber: Data Primer yang diolah, 2019

Pengaruh Pembangunan Plaza Aldiron Terhadap Tingkat Pendapatan Pedagang Tradisional........ 
d. Deskripsi responden berdasarkan status tempat usaha

Tabel 4. Data Responden Berdasarkan Status Tempat Usaha

\begin{tabular}{|c|c|c|c|}
\hline No. & Status Tempat Usaha & Jumlah & Persentase \\
\hline 1 & Menyewa & 45 & $60 \%$ \\
\hline 2 & Milik sendiri & 31 & $40 \%$ \\
\hline & Jumlah & 76 & $100 \%$ \\
\hline
\end{tabular}

Sumber: Data Primer yang diolah, 2019

Tabel 4 di atas menunjukkan bahwa sekitar 45 orang atau $60 \%$ responden didominasi oleh status menyewa, dan sisanya sebesar 31 orang atau $40 \%$ responden oleh status milik sendiri.

\section{HASIL UJI KUALITAS}

\section{Hasil Uji Validitas}

Hasil uji validitas data digunakan untuk mengukur valid atau tidaknya sebuah kuesioner. Suatu kuesioner dinyatakan valid apabila mampu mengungkapkan sesuatu yang akan diukur oleh kuesioner tersebut. Pengujian ini dilakukan dengan menggunakan Pearson Correlation. Apabila Pearson Correlation yang didapat memiliki nilai di bawah 0,05 berarti data yang diperoleh adalah valid. (Ghozali, 2005:45)

Tabel 5 menunjukkan hasil uji validitas dari variabel sebelum ada Pembangunan Plaza Aldiron dengan 76 responden.

Tabel 5. Hasil Uji Validitas Variabel Sebelum Pembangunan Plaza

\begin{tabular}{|c|c|c|c|}
\hline Pernyataan & Pearson Correlation & Sig (2-Tailed) & Keterangan \\
\hline Q1 &, $610(* *)$ &, 000 & Valid \\
\hline Q2 &, $312(* *)$ &, 000 & Valid \\
\hline Q3 &, $581(* *)$ &, 000 & Valid \\
\hline Q4 &, $426(* *)$ &, 000 & Valid \\
\hline Q5 &, $472(* *)$ &, 000 & Valid \\
\hline
\end{tabular}

Sumber: Data Primer yang diolah, 2019

Berdasarkan hasil tabel 5 Di atas menunjukkan bahwa variabel sebelum ada pembangunan Plaza Aldiron terdiri dari 5 butir pernyataan, dari ke 5 butir pernyataan tersebut adalah valid semua. Hal ini dikarenakan nilai signifikan lebih kecil dari 0,05.
Tabel 6 menunjukkan hasil uji validitas dari variabel_ketika ada pembangunan Plaza Aldiron dengan 76 responden. 
Tabel 6. Hasil Uji Validitas Variabel Ketika Pembangunan Plaza

\begin{tabular}{|c|c|c|c|}
\hline Pernyataan & Pearson Correlation & Sig (2-Tailed) & Keterangan \\
\hline Q6 &, $488(* *)$ &, 000 & Valid \\
\hline Q7 &, $532(* *)$ &, 000 & Valid \\
\hline Q8 &, $738(* *)$ &, 000 & Valid \\
\hline Q9 &, $809(* *)$ &, 000 & Valid \\
\hline Q10 &, $818(* *)$ &, 000 & Valid \\
\hline
\end{tabular}

Sumber: Data Primer yang diolah, 2019

Berdasarkan hasil tabel 6 di atas menunjukkan bahwa variabel ketika ada pembangunan Plaza Aldiron terdiri dari 5 butir pernyataan, dari ke 5 butir pernyataan tersebut adalah valid semua.
Hal ini dikarenakan nilai signifikan lebih kecil dari 0,05.

Tabel 7 menunjukkan hasil uji validitas dari variabel pendapatan pedagang tradisional dengan 76 responden.

Tabel 7. Hasil Uji Validitas Variabel Pendapatan Pedagang Tradisional

\begin{tabular}{|c|c|c|c|}
\hline Pernyataan & Pearson Correlation & Sig (2-Tailed) & Keterangan \\
\hline Q11 &, $442(* *)$ &, 000 & Valid \\
\hline Q12 &, $124(* *)$ &, 000 & Valid \\
\hline
\end{tabular}

Sumber: Data Primer yang diolah, 2019

Berdasarkan hasil tabel 7 Di atas menunjukkan bahwa variabel pendapatan pedagang tradisional terdiri dari 5 butir pernyataan, dari ke 5 butir pernyataan tersebut adalah valid semua. Hal ini dikarenakan nilai signifikan lebih kecil dari 0,05.

\section{HASIL UJI RELIABILITAS}

Uji reliabilitas digunakan untuk mengetahui apakah item-item yang ada di dalam kuesioner mampu mengukur perubahan yang didapat dalam penelitian ini (Gozali, 2005). Maksudnya untuk mengukur valid atau tidaknya suatu kuesioner tersebut.

Tabel 8. Hasil Uji Reliabilitas

\begin{tabular}{|c|c|c|}
\hline Variabel & Cronbach's Alpha & N of Items \\
\hline Sebelum ada pembangunan Plaza &, 861 & 5 \\
\hline Ketika ada pembangunan Plaza &, 705 & 5 \\
\hline Pendapatan pedagang tradisional &, 661 & 5 \\
\hline
\end{tabular}

Sumber: Data Primer yang diolah, 2019

Tabel 8 menunjukkan nilai cronbach's alpha atas variabel sebelum ada pembangunan Plaza sebesar 0,861, Pengaruh Pembangunan Plaza Aldiron Terhadap Tingkat Pend variabel ketika ada pembangunan Plaza sebesar 0,705, dan variabel pendapatan pedagang tradisional sebesar 0,661 . tan Pedagang Tradisional.........(Eka Meirawati dkk) 
Sehingga dapat disimpulkan bahwa pernyataan dalam kuesioner semua variabel ini reliable/handal karena mempunyai nilai cronbach's alpha lebih besar dari 0,6. (Ghozali, 2005)

\section{HASIL UJI NORMALITAS}

Pengujian normalitas dilakukan untuk menguji apakah dalam sebuah model regresi, variabel dependen dan variabel independen atau keduanya mempunyai distribusi normal atau tidak.

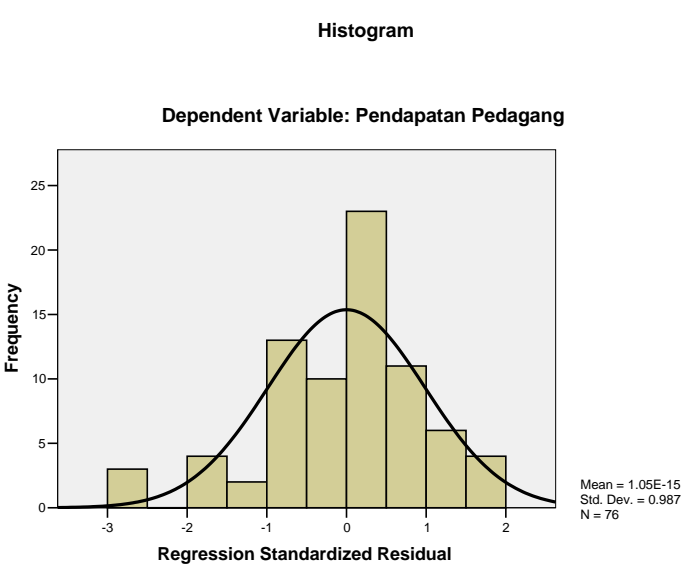

Gambar 1. Normal P-Plot

(Sumber: Data Primer yang diolah, 2019)

Dengan demikian dapat disimpulkan grafik histogram (gambar 1) menunjukkan bahwa model regresi layak dipakai karena asumsi normalitas.

\section{Perbedaan Pendapatan Sebelum dan}

\section{Ketika Pembangunan Plaza Aldiron}

Program revitalisasi pasar yang dilakukan oleh pemerintah Kota Palembang yaitu dengan pembenahan dan penataan pasar di eks Pasar Cinde menyebabkan perubahan pada tempat maupun posisi pedagang los. Beberapa pedagang yang tingkat pendapatannya menurun setelah diadakannya pembenahan pasar mengakui penurunan tingkat pendapatan disebabkan oleh perubahan posisi berjualan. Sebelumnya, beberapa pedagang diuntungkan oleh posisi berdagang yang lebih berada di depan dibandingkan pedagang lainnya yang sejenis. Posisi ini dianggap strategis karena lebih mudah dijangkau oleh pembeli. Ketika program revitalisasi, los-los untuk jenis dagangan yang sama diatur berderet. Ini menyebabkan pembeli dengan mudah berpindah dari satu pedagang ke pedagang lainnya apabila tidak menemukan barang yang diinginkan atau pun apabila tidak ada kesepakatan harga dengan salah satu pedagang. Hal ini menyebabkan persaingan antara pedagang semakin ketat.

Hasil uji statistik $\mathrm{F}$ dapat dilihat pada Tabel 9, jika nilai probability lebih kecil dari 0,05 maka $\mathrm{H}_{\mathrm{a}}$ diterima dan menolak $\mathrm{H}_{\mathrm{o}}$, sedangkan jika nilai probability lebih besar dari 0,05 maka $\mathrm{H}_{\mathrm{a}}$ ditolak dan menerima $\mathrm{H}_{\mathrm{o}}$. (Ghozali, 2005) 


\section{Tabel 9. Annova}

\begin{tabular}{|c|c|c|c|c|c|c|}
\hline \multicolumn{7}{|c|}{ ANOV $A^{b}$} \\
\hline \multicolumn{2}{|c|}{ Model } & $\begin{array}{l}\text { Sum of } \\
\text { Squares }\end{array}$ & $d f$ & Mean Square & $F$ & Sig. \\
\hline \multirow[t]{3}{*}{1} & Regression & 6,491 & 2 & 3,246 & 11,390 &, $000^{a}$ \\
\hline & Residual & 20,803 & 73 & ,285 & & \\
\hline & Total & 27,294 & 75 & & & \\
\hline
\end{tabular}

Sumber: Data Primer yang diolah, 2019

Hasil uji hipotesis dapat dilihat pada tabel 10, variabel sebelum dan ketika ada pembangunan Plaza Aldiron mempunyai tingkat signifikansi sebesar 0,000. Hal ini berarti menerima $\mathrm{H}_{\mathrm{a}}$, sehingga dapat dikatakan bahwa sebelum dan ketika ada pembangunan Plaza Aldiron berpengaruh signifikansi terhadap pendapatan pedagang tradisional karena tingkat signifikansi yang dimiliki variabel sebelum dan ketika ada pembangunan Plaza Aldiron lebih kecil dari 0,05.

Hasil tersebut menunjukkan bahwa sebelum dan ketika ada pembangunan Plaza Aldiron memberikan pengaruh terhadap pendapatan pedagang tradisional pada eks Pasar Cinde. Hasil penelitian ini konsisten dengan penelitian yang Hakim (2003), Sihombing (2010), Dwi Eliyani (2012) menemukan bahwa relokasi pasar tersebut memberikan dampak positif terbukti dengan adanya peningkatan pendapatan dan terciptanya peningkatan interaksi yang baik.

\section{KESIMPULAN}

Berdasarkan hasil penelitian serta hal-hal yang terkait dengan keterbatasan penelitian ini, maka dapat diberikan rekomendasi sebagai berikut:

1. Bagi penelitian selanjutnya dapat menambahkan faktorfaktor lainnya yang terkait dengan pembangunan pasar, misalnya dari segi permodalan pedagang, segi kenyamanan pasar, segi parkir, segi kebersihan, dan lain-lain.

2. Perlu dilakukan pengembangan instrumen penelitian, yaitu disesuaikan dengan kondisi dan lingkungan dari obyek yang akan diteliti. Selain itu perlu dilakukan pilot study untuk menjamin bahwa item-item pertanyaan dalam kuesioner dapat dipahami dengan baik oleh responden.

3. Peran instansi terkait menangani permasalahan yang dialami pedagang tradisonal eks Pasar Cinde adalah oleh Dinas Pasar dengan penataan dan 
memberlakukan pengaturan terhadap para pedagang yang nantinya akan menempati Plaza Aldiron.

\section{DAFTAR PUSTAKA}

E. Kieso,Donald, Jerry J, Weygandt and Teery D. Warfield. 2016. Accounting Principles. 12th Edition. Jakarta: Salemba Empat.

E. Kieso,Donald, Jerry J, Weygandt and

Teery D. Warfield. 2016. Intermediate Accounting. $12^{\text {th }}$ Edition. Jakarta: Salemba Empat.

Ghozali, Imam. 2018. Aplikasi Analisis Multivariat Dengan Program SPSS. Semarang : BP Undip.

Horngren, Charles $\mathrm{T}$ dan Foster, George. Akuntansi Biaya. Jakarta: Erlangga

Ikatan Akuntan Indonesia. 2020. Standar Akuntansi Keuangan. Penerbit Salemba Empat. Jakarta.

M.Munandar. 2006. Pokok-Pokok Intermediate Accounting. Gajah Mada University Press: Yogyakarta.

Peraturan Menteri Perdagangan No. 53/M-DAG/PER/12/2008 tentang Pedoman Penataan dan Pembinaan Pasar Tradisional, Pusat Perbelanjaan dan Toko Modern.

Reardon, Thomas and Julio A. Berdegué. 2002. The Rapid Rise of Supermarkets in Latin America: Challenges and Opportunities for Development. Development Policy Review.

Reardon, Thomas, C. Peter Timmer, Christopher B. Barrett, and Julio Berdegué. 2003. The Rise of Supermarkets in Africa, Asia, and
Latin America. American Journal of Agricultural Economics.

Reardon, Thomas and Rose Hopkins. 2006. The Supermarket Revolution in Developing Countries: Policies to Address Emerging Tensions among Supermarkets, Suppliers, and Traditional Retailers. European Journal of Development Research.

Sarief, Saifuddin. 2004. Kebijakan untuk Meningkatkan Iklim yang Kondusif dalam Mengembangkan UMKM sebagai Kekuatan Ekonomi.

Sarwoko, Endi. 2008. Dampak Keberadaan Pasar Modern Terhadap Kinerja Pedagang Pasar Tradisional Di Wilayah Kabupaten Malang. Jurnal Ekonomi Modernisasi, Vol. 4 No.2, 2008,97-115. 